\title{
3D Virtual Learning Environment
}

\author{
Wan Abdul Rahim Wan Mohd Isa, Ahmad Iqbal Hakim Suhaimi, \\ Nurulhuda Noordin, Nor Azilah Othman
}

\begin{abstract}
Virtual Learning Environment (VLE) is the learning through electronic media where teachers and students are not in the same place, but the gap is bridged by the use of technologies. The aim of this study is to develop a $3 D$ virtual learning environment (3D VLE). The three objectives of this study are (i) to gather the requirements of $3 D V L E$, (ii) to design the $3 D V L E$, and (iii) to develop the $3 D V L E$. The method consists of five phases; (i) literature review, (ii) requirement gathering, (iii) design, (iv) development and (v) evaluation. The prototype is developed by using Open Simulator, SLOODLE and Moodle. Future work includes enhancement for $3 D$ VLE such as using gesture recognition to control the avatar movement.
\end{abstract}

Keywords: Human computer interaction, virtual learning, mobile learning, $3 D$, virtual learning environment.

\section{INTRODUCTION}

There are various teaching and learning approaches such as face-to-face learning, e-learning, and also a virtual classroom. Face-to-face teaching and learning approach can be considered as a traditional learning method. It has a lot of advantages such as direct image from both students and teachers, convenient communication and ease of use of different graphic and text [1], however the face to face learning need all facilities in one place, consume a large space, student and teacher's compulsories in one place, and time conflict because of the class scheduling.

Virtual learning or e-learning is one of the approaches that used to overcome the face-to-face learning approaches disadvantages. Virtual Learning Environment (VLE) as learning through electronic media where teachers and students are not in the same place, but the gap is bridged by the use of technologies. There are various types of virtual learning such as e-learning, mobile learning, social networking, and virtual classroom [2].

VLE is the advance learning approach that allow students to communicate with teachers over the internet. It offers active interaction and engagement with tools for online participation. VLE basically employs multiple synchronous technologies such as online whiteboard, tools for

Revised Manuscript Received on September 22, 2019.

Wan Abdul Rahim Wan Mohd Isa, Centre of Information Technology Studies, Faculty of Computer and Mathematical Sciences, Universiti Teknologi MARA, Shah Alam, Selangor, Malaysia.

Ahmad Iqbal Hakim Suhaimi, Centre of Information Technology Studies, Faculty of Computer and Mathematical Sciences, Universiti Teknologi MARA, Shah Alam, Selangor, Malaysia.

Nurulhuda Noordin, Centre of Information Technology Studies, Faculty of Computer and Mathematical Sciences, Universiti Teknologi MARA, Shah Alam, Selangor, Malaysia.

Nor Azilah Othman, ASCOTT International Management Malaysia, Malaysia. presentation, video conferencing, chat, messages and contain different graphic input such as pdf format, powerpoint and 3D model [3]. VLE presents several advantages where it enhances student-centered learning, the student becomes more self-sufficient and it can help the teachers or educators can be more innovative in preparing learning resources. There are various kinds of design of VLE such as developing VLE using cloud computing, web-based, text to visual speeches, hand gesture, eye recognition and 3D virtual reality. The 3D virtual learning environment is a computer representation of real-world of imaginary spaces and interacts with the object in real-time [4].

\section{VIRTUAL LEARNING ENVIRONMENT}

Information and Communication Technologies (ICT) should corporate with Higher Educational Institutions (HEIs) in current content learning and teaching processes to achieve better outcomes for student learning. VLE is computer-based environments that allowing interaction between student and educator to a wide range of resources [5]. VLE also can be defined as a classroom where students and educators can be communicating in different places and locations [6]. The role of VLE focusing on systems characteristics such as; (i) course content presentation, (ii) facilitate communication and interaction, (iii) presentation of course content and logistics as essential functions of these tools [7]. The implementations of VLE in interactions and discussions are through course management tools and activities, task or file management and classrooms [8]. The consideration of using the VLE as a collaboration content, used for simulation and animation, help to create e-repository for the related problem and also to enhance interaction and communication for student [9]. The comparison for example of virtual learning can be seen in Table I.

VLE can be implemented in many ways depending on the situation and requirements of the higher institutions. Many universities offer online or MOOC courses with VLE. The theoretical framework for the VLE implementation refers to the pedagogical perspective of instructional design [10].

Nowadays, a student can implement these technologies to access or get the notes or class information, communicate and interact with each other, and also do an online assessment. The usage of the virtual learning environment and higher education could enhance student engagement and can be as effective learning for those who are not interested in traditional learning and also can build their confidence level [11]. 


\section{D Virtual Learning Environment}

In order to achieve a high-quality education, a methodology in the planning, design and usage of virtual classrooms is imperative and should comprise the resources, tasks, activities, evaluation and assessment strategies associated with the learning and teaching process [12].

Table- I: Comparison of Virtual Learning (VL)

\begin{tabular}{|l|l|l|l|}
\hline VL & $\begin{array}{l}\text { Web-Based Interactive Virtual } \\
\text { Classroom }\end{array}$ & $\begin{array}{l}\text { 3D Interaction and Real-Time } \\
\text { Motion Detection }\end{array}$ & Gesture Recognition \\
\hline Example & $\begin{array}{l}\text { Application that runs on web-based } \\
\text { and the platform will have focused } \\
\text { on web technology \& also platform } \\
\text { independence [13] }\end{array}$ & $\begin{array}{l}\text { Computer representation of } \\
\text { real-world of imaginary spaces \& } \\
\text { interaction with object in } \\
\text { real-time [4] }\end{array}$ & $\begin{array}{l}\text { Gesture as meaningful body } \\
\text { motion to convey meaningful } \\
\text { information \& interaction with } \\
\text { the environment }\end{array}$ \\
\hline Scope & $\begin{array}{l}\text { Supports traditional classroom } \\
\text { training and online learning } \\
\text { environments \& classroom } \\
\text { independence and also platform } \\
\text { independence [13] }\end{array}$ & $\begin{array}{l}\text { Usually used in virtual reality } \\
\text { technology. } \\
\text { Provide real-time learning where } \\
\text { user can travel around the 3D } \\
\text { world, walk on campus, entering } \\
\text { a classroom [14] }\end{array}$ & $\begin{array}{l}\text { Virtual environment } \\
\text { navigation, video conferencing } \\
\text { interface efficiency } \\
\text { [15] }\end{array}$ \\
\hline
\end{tabular}

There are a few examples of VLE that are developed to meet the need of the new generation of HEIs student and educators, some of the techniques are using 3D interaction [1], [16], text to visual speeches [17], virtual classroom environment with gesture recognition (Kinect) [6], cloud computing with VLE model [18], and web-based interactive VLE using HTML5 [3].

\section{METHOD}

\section{A. Proposed Architecture for 3D VLE using SLOODLE}

The proposed architecture design for this research are developed based on SLOODLE [19]. There are three types of users involved which are students, educators and administrators. There are communicating using a 3D virtual learning environment (3D VLE) interface that is developed using OpenSim. The user will be represented by a selected avatar. The user will be interacting with a learning management system that is using Moodle. The user will able to access Moodle and OpenSim via the web browser and the server-side will check whether the user has permission and authorization to the system. In principle, the same happened when a user interacts with the data in the Moodle database using SL client, where the request will handle by the SLOODLE module in the server. Fig. 1 shows the proposed architecture for 3D VLE.

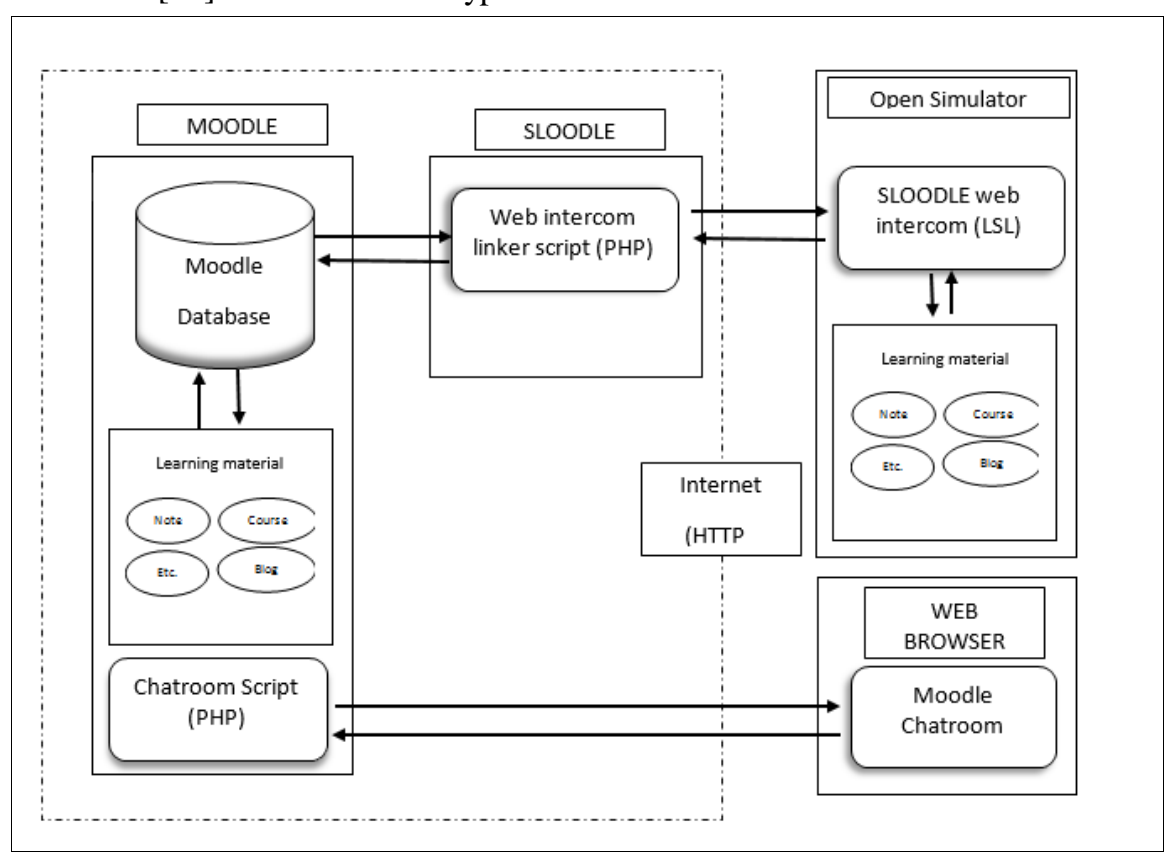

Fig. 1. Proposed Architecture for 3D VLE 


\section{B. Research Methodology}

The ADDIE model is an approach that helps instructional designers to create an efficient and effective teaching design to the product or system [20]. ADDIE model originally consists of five phases which are analysis phase, design phase, development phase, implementation phase, and evaluation phase. The understanding of the ADDIE model provides insights to the development of 3D Virtual Learning Environment.

For this research, the development of 3D Virtual Learning Environment consists of five phases which are (i) systematic literature review phase, (ii) interview phase, (iii) design phase, (iv) development phase and (v) evaluation phase. The systematic literature review phase is a process of identifying the characteristic and concept of 3D VLE, while the interview phase is a process to identify the requirement on developing 3D VLE. The design phase is a phase of designing the storyboard and also proposed architecture design, while the development phase involved identifying the software, the hardware used and also the programming language used for developing the prototype. The last phase is the evaluation phase which this phase will evaluate the motivational dimension.

\section{- Phase 1: Literature Review}

Literature review phase is a stage that aims to address the problem by identifying, critical analyzing, and integrating the finding of all relevant individual studies addressing one or more research questions. The research question that needs to be answered during this stage is the characteristic and concept of the virtual learning environment. The outcome from this phase have identified the characteristic of the virtual learning environment and the concept of the virtual learning environment.

\section{- Phase 2: Requirement Gathering}

The interview phase is the stage that aims to explore the views, experiences, belief and motivational of individual on the virtual learning environment. From the interview, there will be a deeper understanding of the requirements needed. The three interviewees selected are (i) Halimah, (ii) Farahan and (iii) Marina. Each interviewee has been asked ten questions related to the virtual learning environment. Based on this interview, three important requirements for developing the virtual learning environment are identified.

The design phase is to determine specific competencies, methods, teaching materials and learning strategies in developing this project. It is involved in designing the system based on the chosen hardware, software and any related item. In this project, the OpenSim is chosen as the $3 \mathrm{D}$ virtual world, while Moodle as the learning material and SLOODLE as a tool simulation-based learning which integrates the OpenSim and Moodle.

\section{- Phase 3: Design}

The design phase is the third phase, after the requirements are identified as initial input, design elements are built for each requirement including the functional diagram, screen layout, entity relationship diagram and also storyboard. The research question is what is the design architecture and also the storyboard of 3D VLE. Fig. 1 shows the proposed architecture design for 3D VLE using SLOODLE architecture. Based on the proposed architecture design, the 3D VLE involved three components (i) learning management system (Moodle), (ii) 3D virtual environment (OpenSim) and (iii) SLOODLE architecture (integration between Moodle and SLOODLE).

\section{- Phase 4: Development}

The development phase is a stage of identifying the technology that will be used to develop the prototype. For 3D VLE, technologies including software, hardware, and also a programming language. The 3D VLE software is using Moodle, Open Simulator, SLOODLE, apache as a web server, and MySQL as a database server. A local server is being used. The 3D VLE using programming language $\mathrm{C}$ and PHP. The prototype is developed during this phase, after the prototype is ready, there will be an evaluation phase.

\section{- Phase 5: Evaluation}

The final process in the evaluation phase and may be done by measuring the motivational dimension.

\section{RESULTS}

\section{A. Results Phase 1: Literature Review}

Based on the analysis of literature review, below is the final finding of the concept and characteristic of the $3 \mathrm{D}$ virtual learning environment. Hypertext course is the most well-known VLE concept, where the learning material is provided electronically and can also be view using the browser. The second concept is video-based and audio based courses where lecturer prepared slide or online examples using the illustration. The third one is an animated course where animation is created using multimedia technologies such as flash or similar technologies.

For this project, the virtual learning environment implemented the hypertext courses, video-based and animated course. Table II shows examples of virtual learning

The characteristic of a virtual learning environment is also being analyzed and then summarized. The virtual learning environment must offer freedom in learning where it can be accessed anywhere and anytime. The most important characteristic of VLE is they can offer freedom in learning where educators and students didn't need to be in the same place and at the same time.

The class method must help the student to understand the content better. The content document and material must be easy to access and stored. The teaching method needs to be various such as involve a 3D object, audio, and game. Table III shows the summarized characteristic of a virtual learning environment based on the literature review of related studies.

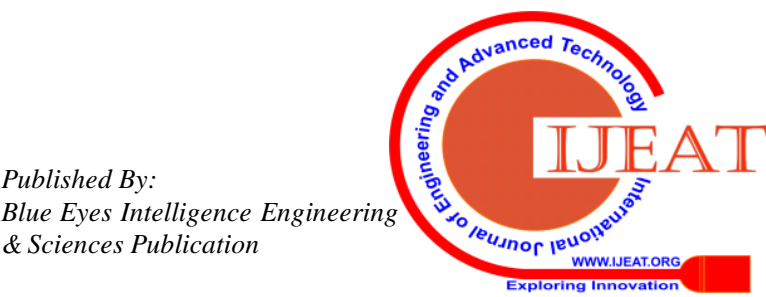


Table- II: Example of Implementation of VL

\begin{tabular}{|c|c|c|}
\hline $\mathrm{VL}$ & Description & References \\
\hline Hypertext courses & $\begin{array}{l}\text { Learning material is provided electronically through the } \\
\text { hyperlink (multimedia parts, text and exercise connecting } \\
\text { in a meaningful way) }\end{array}$ & $\begin{array}{l}{[2],[10],} \\
{[21]}\end{array}$ \\
\hline $\begin{array}{l}\text { Video-based and } \\
\text { audio-based courses }\end{array}$ & $\begin{array}{l}\text { Streaming technologies or videos. The recording of face to } \\
\text { face interaction and slides. }\end{array}$ & $\begin{array}{l}{[2],[10],} \\
{[22],[23]}\end{array}$ \\
\hline Animated courses & $\begin{array}{l}\text { The animated courses are created using multimedia } \\
\text { technologies such as flash or similar technologies. }\end{array}$ & $\begin{array}{l}{[2],[21],} \\
{[22]}\end{array}$ \\
\hline $\begin{array}{l}\text { Web-supported } \\
\text { textbook courses }\end{array}$ & $\begin{array}{l}\text { Students will read, review and do chapter reflections. } \\
\text { Discussions can be done with educators over the internet or } \\
\text { chatroom. }\end{array}$ & {$[2],[22]$} \\
\hline
\end{tabular}

Table- III: Characteristics of Virtual Learning Environment

\begin{tabular}{|l|l|}
\hline \multicolumn{1}{|c|}{ Characteristic of VLE } & \multicolumn{1}{c|}{ References } \\
\hline Location of learning - Offer freedom in learning anywhere and anytime. & {$[5],[11],[23],[24]$} \\
\hline $\begin{array}{l}\text { Learning Process - Offer independent study where individual task and } \\
\text { learning material found in various resources. }\end{array}$ & {$[10],[12],[23],[24]$} \\
\hline Visualization for difficult content. & {$[10],[11],[23]$} \\
\hline Resources - Availability of document and materials of instruction. & {$[5],[10],[22]$} \\
\hline Interaction - Real time communication using text, and voice based. & {$[10],[11],[22],[23]$} \\
\hline Course content are interactive using audio, video, and meet the objective. & {$[10],[11],[22],[24]$} \\
\hline
\end{tabular}

\section{B. Results Phase 2: Requirement Gathering}

The interview was conducted in June 2016 with three students. They are part-time students of Master of Science in Information Technology. The interview aims is to gather requirements to develop 3D VLE. Based on the interview, there are three requirements identified to be the most important requirements needed in 3D virtual learning environment development.

- The usage of audio, video, and visual content at VLE

"......VLE must be interactive enough such as music, video and can be automatic education plays" (P1)

"...... maybe can include interactive content such as video, $3 D \ldots \ldots .,(\mathrm{P} 2)$

"....... be interactive with various resources and various learning material such as graphic, audio, use of visual and many more" (P3)

Above are the qualitative responses from the respondents that explain the importance of using audio and video in the virtual learning environment. Three of the interviewees believe that to develop a good VLE, the developer should consider the usage of the audio, visual, audio to the content or the environment itself.

- Interaction and communication among student and educator
"VLE must have a better interaction between student and lecturer......" (P1)

“...... The content of VLE must have more animation, real time communication using chat." (P2)

"....... Efficient when 2-ways communication and interaction exist” (P3)

Above are the qualitative response from the respondents that explain that to develop VLE, one of the important requirement must provide interaction and improve communication among student and lecturer. The communication can be either using chat, forum, or real-time chat using an avatar.

- Availability and can be accessed anytime and everywhere

"......minimize our time to the physical class, so we can access the VLE everywhere...... " (P1)

"......expect to have access to that community on almost a 24/7 basis" ( $\mathrm{P} 2)$

“.... students do not have to travel far just to enroll for classes" (P3)

Above are the qualitative responses from the respondents that explain the importance of the availability of the VLE. They believe that VLE must be available 24/7, and can be accessed everywhere such as at home, office, or any place that 
has internet access. All of these requirements will be used when developing a 3D VLE design.

\section{Result Phase 3: Design}

Based on the design phase, the result of the process flow, entity-relationship diagram, screen capture and storyboard is explained in below subsections.

\section{- Storyboard of 3D VLE}

The storyboard of 3D VLE is in a form of image and illustration displayed in sequence for the purpose of planning the direction of developing the actual 3D VLE prototype.

\section{- System Flowchart of 3D VLE}

There are several processes taken into consideration before developing 3D VLE. The process flow involves the flow of learning management system, SLOODLE architecture flow which is the architecture that makes LMS and 3D environment communicate with each other, and the last one is the flow of the 3D environment. For this 3D VLE, Moodle is chosen as LMS and OpenSim as a 3D environment. Fig. 2 shows the overall process flow of 3D VLE.

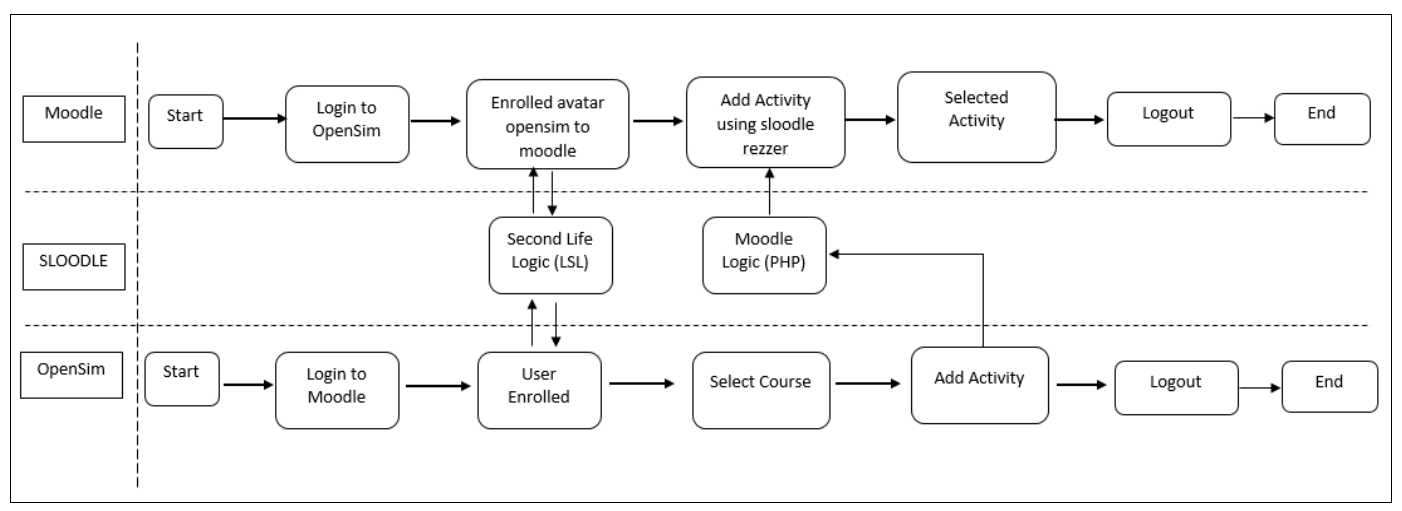

Fig. 2. Process Flow of 3D Virtual Learning Environment

The user will log in either using Moodle or OpenSim and then enrolled in a course before they can add an activity. The enrolled user using OpenSim with SLOODLE Rezzer and LSL and the user at OpenSim can add activity from Moodle using Moodle logic which is in PHP language.

Moodle process flow consists of the flow for the administrator for user registration. It starts from registering the user and then adding a course for the user, after that select and choose an activity to include in a course such as a quiz, assignment, forum and chat. For one course, users can add multiple activities and the most important thing is users need to enroll in the course before they can access the content or activity provided. Fig. 3 shows the process flow of Moodle.

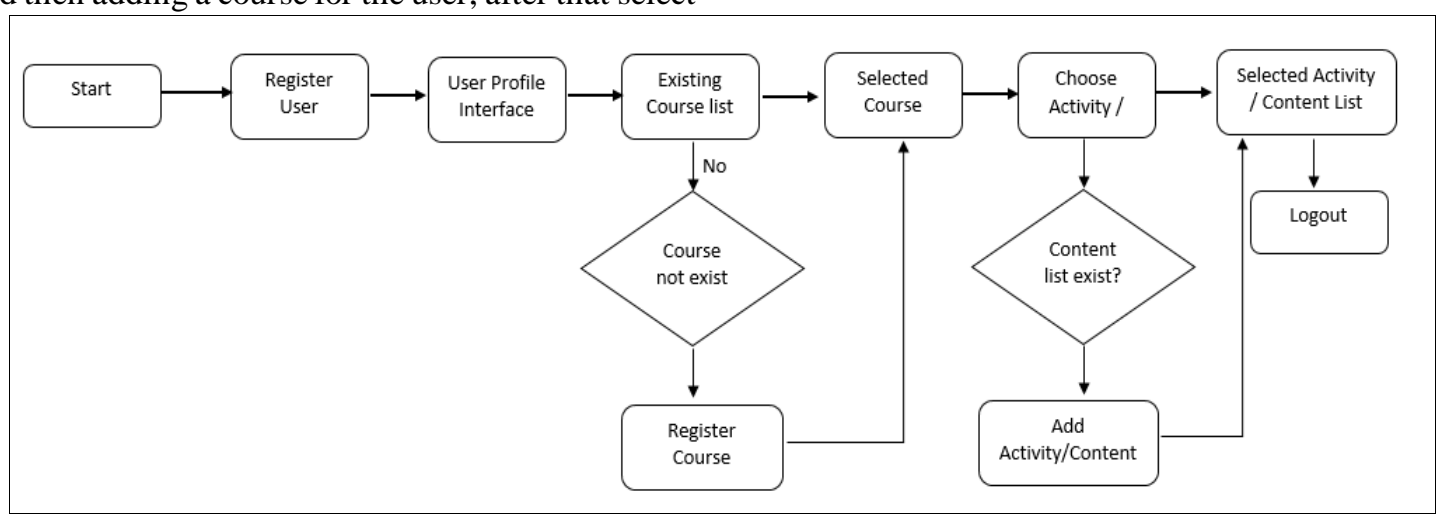

Fig. 3. Process Flow of Learning Management System (Moodle)

OpenSim is open-source software that provides the 3D environment or virtual world. It is represented by an avatar and 3D content. The flow is users need to login to OpenSim and they need to register an avatar to Moodle using SLOODLE rezzer before they can add and access an activity such as quiz, presenter, and content. For using SLOODLE architecture, the user needs to login to OpenSim, and they will have used SLOODLE rezzer as a communicated object to Moodle, while for Moodle SLOODLE configuration plugin needs to be installed before it can communicate with OpenSim. Fig. 4 and Fig. 5 show the overall process flow when using OpenSim and SLOODLE. 


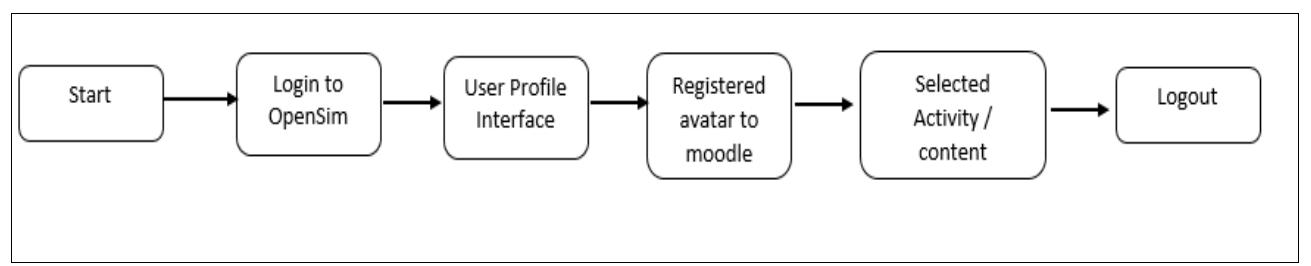

Fig. 4. Process Flow of Virtual Learning Environment (OpenSim)

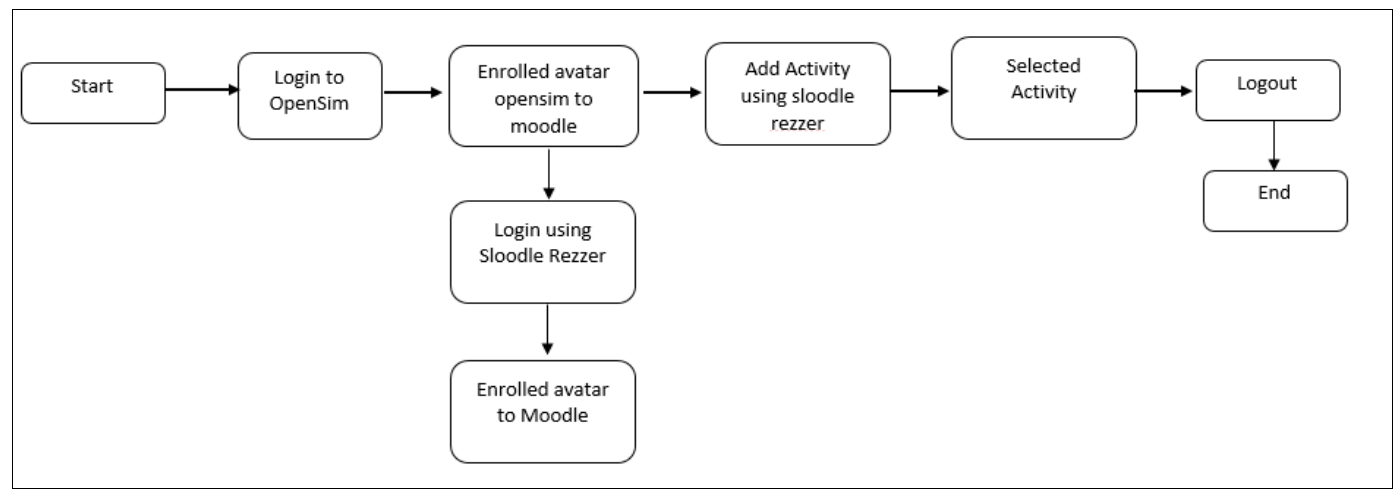

Fig. 5. Process Flow of SLOODLE

- Entity Relationship Diagram

In 3D VLE development, there are eight tables involved which are admin, user, course, quiz, question, assignment, chat, and forum. Table IV briefly describes each table function.

Table- IV: 3D VLE Table Description

\begin{tabular}{|c|c|l|}
\hline No & Table & \multicolumn{1}{|c|}{ Description } \\
\hline 1 & Admin & $\begin{array}{l}\text { Stored all admin functions and admin information. } \\
\text { The table is created during the configuration of the } \\
\text { learning management system (Moodle) as per this } \\
\text { project used. }\end{array}$ \\
\hline 2 & User & $\begin{array}{l}\text { Stored all user information, cache, and detail of } \\
\text { users such as courses registered, detail information, } \\
\text { and also enrollment courses. }\end{array}$ \\
\hline 3 & Course & This table stored all detail of courses registered. \\
\hline 4 & Quiz & $\begin{array}{l}\text { This table stored all quizzes added and the history of } \\
\text { all quizzes. }\end{array}$ \\
\hline 5 & Question & $\begin{array}{l}\text { This table stored the question created before. It can } \\
\text { be used again and will be stored in the question bank. }\end{array}$ \\
\hline 6 & $\begin{array}{c}\text { Assignmen } \\
\mathrm{t}\end{array}$ & $\begin{array}{l}\text { Stored all assignment information created by an } \\
\text { admin. }\end{array}$ \\
\hline 7 & Chat & $\begin{array}{l}\text { The chat function that will store history and the } \\
\text { current chatting environment. }\end{array}$ \\
\hline 8 & Forum & $\begin{array}{l}\text { This table will store forum information and the } \\
\text { detail of each forum created. }\end{array}$ \\
\hline
\end{tabular}

The quiz, assignment, chat, and forum later can be used to be added at the OpenSim environment. OpenSim will gather information at each table and display all the information at the OpenSim interface. Fig. 6 shows the entity relationship diagram for each table. One admin can create many users and for Moodle, there is only one admin. Each user has many different roles and the selected role can create many courses.
One course can have multiple quizzes, forums, chats, and assignments. One quiz can also have multiple questions and one question can be added to multiple quizzes. Each quiz, forum, chat, and assignment can be added more than one to each course. 


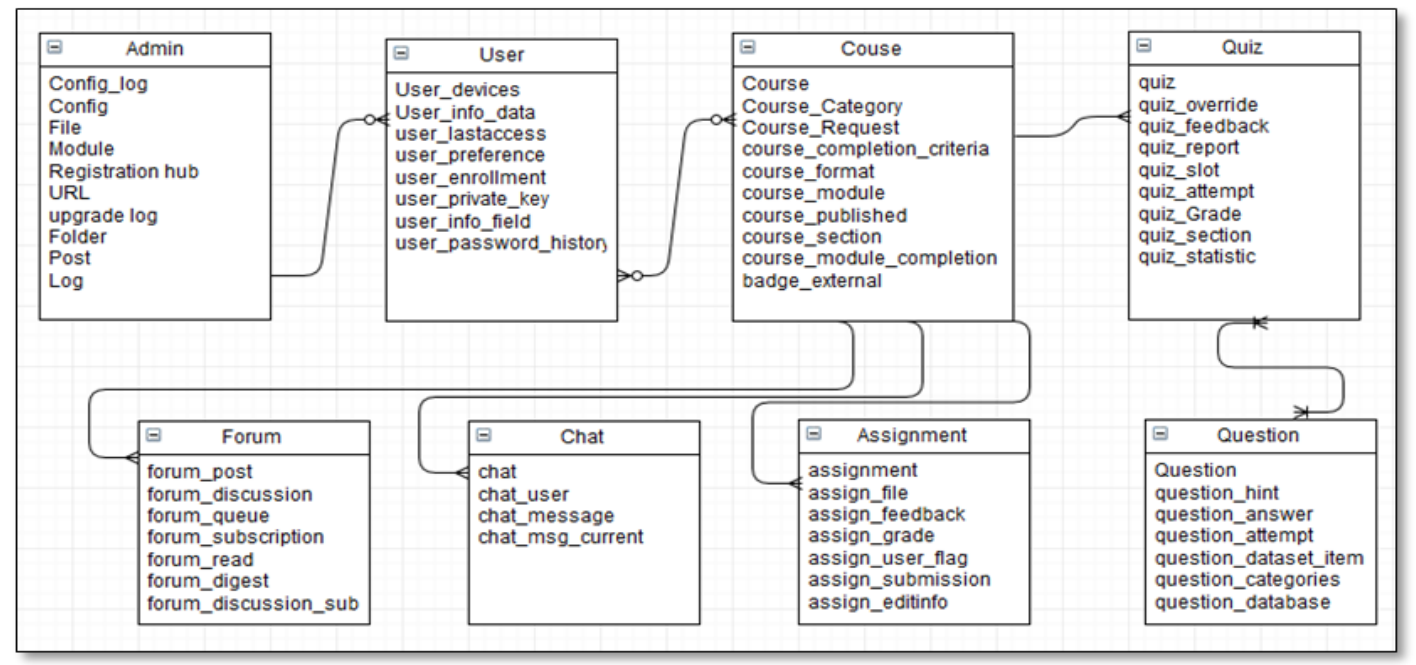

Fig. 6. Entity Relationship Diagram of Learning Management System (Moodle)

\section{Result Phase 3: Design}

For the development phase of this project, SLOODLE OpenSim, PHP language, MySQL and Apache web server were used.

\section{CONCLUSION}

The 3D virtual learning environment can assist educators to provide more interactive learning and can be easily used for distance learning students. There are various research on cloud computing [25] and blended learning and mobile learning [26] - [30] that may facilitate the 3D virtual learning environment. It offers a different learning environment and each student can communicate with other students via online and represent by an avatar. Future work includes enhancement for 3D VLE such as using gesture recognition to control the avatar movement.

\section{ACKNOWLEDGMENT}

This research is funded by the Research Entity Initiative (REI), Universiti Teknologi MARA, Malaysia. (Project Code: 600-IRMI/REI 5/3 (013/2018).

\section{REFERENCES}

1. S. Sharma and W. Chen, "Multi-user vr classroom with $3 \mathrm{~d}$ interaction and Computational Science and Computational Intelligence, Las Vegas, NV, USA, 2014, pp. 187-192.

2. S. Rawal, and U. S. Pandey, "E-learning: learning for smart generation z," International Journal of Scientific and Research Publications, vol. 3, no. 5, 2013, pp. 1-5.

3. N. Buasri, T. Janpan, U. Yamborisut, and D. Wongsawang, "Web-based interactive virtual classroom using html5-based technology," 2014 Third Pathom, 2014, pp. 33-36.

4. J. Jankowski, and M. Hachet, "Advances in interaction with $3 \mathrm{~d}$ environments," Computer Graphics Forum, vol. 34, no. 1, 2015, pp. 152-190.

5. N. F. B. Sa'don, H. B. Mohamed Dahlan, and H. B. Zainal, "Derivation for design of virtual learning environment (vle) framework for malaysian schools," 2013 International Conference on Research and Innovation in Information Systems (ICRIIS), Kuala Lumpur, 2013, pp. 570-575.

6. B. Hariharan, S. Padmini, and U. Gopalakrishnan, "Gesture recognition using kinect in a virtual classroom environment," 2014 Fourth International Conference on Digital Information and Communication architecture and several technologies including Moodle, real-time motion detection," in 2014 International Conference on ICT International Student Project Conference (ICT-ISPC), Nakhon

Technology and its Applications (DICTAP), Bangkok, 2014, pp 118-124.

7. E. Lavolette, M. A. Venable, E. Gose, and E. Huang, "Comparing synchronous virtual classrooms: student, instructor and course designer perspectives," TechTrends: Linking Research \& Practice to Improve Learning, vol. 54, no. 5, 2010, pp. 54-61.

8. F. Martin, "Best practices for teaching in a synchronous virtual classroom," 2010 International Conference on Technology for Education, Mumbai, 2010, pp. 44-46.

9. K. Moscinska, and J. Rutkowski, "Barriers to introduction of e-learning: A case study," 2011 IEEE Global Engineering Education Conference (EDUCON), Amman, 2011, pp. 460-465.

10. A. A. Ahmed, N. H. Zakaria, and A. H. Elmi, "An evaluation of virtual learning environment readiness in higher education institutions (heis)," Journal of Information Systems Research and Innovation, 2012, pp. 86-94.

11. V. Jaligama, and F. Liarokapis, "An online virtual learning environment for higher education," 2011 Third International Conference on Games and Virtual Worlds for Serious Applications, Athens, 2011, pp. 207-214.

12. M. Peñafiel, L. Vintimilla, S. Luján-Mora, and P. P. Montesdeoca, "Analysis of the usage of virtual classrooms in the national polytechnic school of ecuador: teachers' perception," 2015 International Conference on Information Technology Based Higher Education and Training (ITHET), Lisbon, 2015, pp. 1-6.

13. P. Brusilovsky, "Adaptive and intelligent technologies for web-based education," In C. Rollinger \& C. Peylo (Eds.) Künstliche Intelligenz 4, Special Issue on Intelligent Systems and Teleteaching, 1999, pp. 19-25.

14. M. T. Valdez, C. M. Ferreira, M. J. M. Martins, and F. P. M. Barbosa, "3D virtual reality experiments to promote electrical engineering education," 2015 International Conference on Information Technology Based Higher Education and Training (ITHET), Lisbon, 2015, pp. 1-4.

15. S. Mitra, and T. Acharya, "Gesture recognition: a survey," IEEE Transactions on Systems, Man, and Cybernetics, Part C (Applications and Reviews), vol. 37, no. 3, 2007, pp. 311-324.

16. I. Branovic, R. Popovic, N. Jovanovic, R. Giorgi, B. Nikolic, and M Zivkovic, "Integration of simulators in virtual $3 \mathrm{~d}$ computer science classroom," 2014 IEEE Global Engineering Education Conference (EDUCON), Istanbul, 2014, pp. 1-4.

17. Z. Yang, F. Cheng, and D. Zhang, "A virtual classroom platform based on text to visual speeches," 2008 IEEE International Symposium on IT in Medicine and Education, Xiamen, 2008, pp. 312-315.

18. N. Wilaisakoolyong, "Using cloud computing systems to create virtual classroom model for thai-nichi's students," 2015 5th International Conference on IT Convergence and Security (ICITCS), Kuala Lumpur, 2015, pp. 1-4.

19. Z. Guomin, and Z. Jianxin, "An educational value analysis of sloodle-based distributed virtual learning system," 2010 Second International Workshop on Education Technology and Computer Science, Wuhan, 2010, pp. 402-405.

20. N. Aldoobie, "Addie model," American International Journal of Contemporary Research, vol. 5, no. 6, 2015, pp. 68-72.

21. M. Turoff, and S. R. Hiltz, "Software design and the future of the virtual classroom $\AA$," Journal of Information Technology for Teacher Education, vol. 4, no. 2, 1995, pp. 197-215. 
22. M. H. Siddiqui, "Virtual classroom learning for higher education: a result of information technology," International Journal of Management and Social Sciences Research (IJMSSR), vol. 2, no. 2, 2013.

23. E. Palomäki, "Applying 3d virtual worlds to higher education," M.Sc. (Tech.) Thesis. Espoo: Helsinki University of Technology, Faculty of Information and Natural Sciences, 2009.

24. H. El Kabtane, Y. Mourdi, M. El Adnani, and M. Sadgal, "The integration of augmented reality in the virtual learning environment for practical activities," 2015 International Conference on Electrical and Information Technologies (ICEIT), Marrakech, 2015, pp. 363-368.

25. W. A. R. Wan Mohd Isa, A. I. H. Suhaimi, N. Noordin, A. F. Harun, J. Ismail, and R. Awang Teh, "Cloud computing adoption reference model," Indonesian Journal of Electrical Engineering and Computer Science, vol. 16, no. 1, 2019, pp. 395-400.

26. W. A. R. W. M. Isa, A. M. Lokman, M. N. Mustapa, I. N. M.Sah, A. R. Hamdan, and J. E. Luaran, "Exploring new factors for m-learning adoption in blended learning environment", Information (Japan), vol. 19, no. 10, pp. 4743-4747, 2016.

27. W. A. R. W. M. Isa, A. M. Lokman, I. N. M. Sah, A. R. Hamdan, and J. E. Luaran, "Framing grounded theory method (gtm) in blended learning adoption patterns: a research framework," Advanced Science Letters, vol. 22, no. 10, 2016, pp. 3011-3013.

28. W. A. R. W. M. Isa, A. M. Lokman, M. R. Megat Adnan, I. N. Mat Sah, A. R. Hamdan, and J. E. Luaran, "Assessing m-learning readiness in blended learning environment: an empirical investigation," Advanced Science Letters, vol. 22, no. 10, 2016, pp. 3151-3154.

29. W. A. R. W. M. Isa, A. M. Lokman, M. R. M. Adnan, I. N. M. Sah, A. R. Hamdan, and J. E, Luaran, "Factors of using m-learning in blended learning environment: a qualitative inquiry," Advanced Science Letters, vol. 22, no. 10, 2016, pp. 3155-3158.

30. W. A. R. W. M. Isa, "A conceptual model of m-learning adoptions," ARPN Journal of Engineering and Applied Sciences, vol. 11, no. 3, 2016, pp. 1978-1982.

\section{AUTHORS PROFILE}

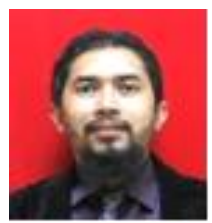

Associate Professor Ts. Dr. Wan Abdul Rahim Wan Mohd Isa is an Associate Professor from Faculty of Computer and Mathematical Sciences, Universiti Teknologi MARA, Shah Alam, Selangor, Malaysia. His research interests include Human Computer Interaction, IT Management and Mobile Learning and Technologies. He leads the Mobile Learning and Technology Research Group, Universiti Teknologi MARA and received professional certification as a Professional Technologist from Malaysia Board of Technologists. He is the Head of Academic Curriculum, Universiti Teknologi MARA and currently the Distinguished Speaker of the Association for Computing Machinery.

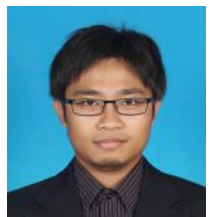

Ahmad Iqbal Hakim Suhaimi is a senior lecturer from Faculty Computer and Mathematical Sciences, Universiti Teknologi MARA, Shah Alam, Selangor, Malaysia. He received his Bachelor of Engineering (Information \& Computer Sciences), Master of Engineering (Mathematics, Electronics \& Informatics), and Doctor of Philosophy (Science and Engineering) from Saitama University, Japan in 2009, 2011, and 2014 respectively. His research interests include information security management, IT infrastructure, and IT service management. He is also certified in ITIL Foundation Certification and ITIL Intermediate Certification (Service Operation) since 2011 and 2019 respectively.

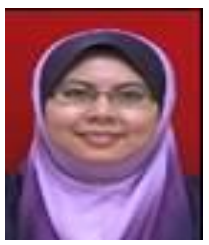

Nurulhuda Noordin is a Senior Lecturer from the Centre of Information Technology Studies, Faculty of Computer and Mathematical Sciences, Universiti Teknologi MARA Shah Alam, Selangor, Malaysia. Her expertise and research interest include Halal Certification Systems, strategic IT and Human Computer Informatics. She holds an Alibaba E-Commerce Talent Global Lecturer Certification since 2017. Her recent researches are on virtual technology on the halal certification system and IR 4.0 in teaching and learning. Currently, she is a Coordinator for the Computer Sciences Servicing Program at Faculty of Computer and Mathematical Sciences, Universiti Teknologi MARA Shah Alam, Malaysia.

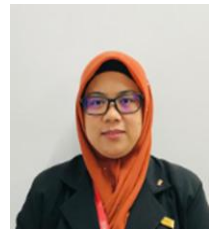

Nor Azilah Othman is an Assistant IT Manager at ASCOTT International Management Malaysia. She received her bachelor's degree in Information Technology from University Tun Hussein Onn, Malaysia in June 2010 and Master of Science in Information Technology from Universiti Teknologi MARA, Shah Alam, Selangor, Malaysia in May 2017. She has a background in software and system administration and holds keen interest in the area of IT networking and IT auditing. 